\title{
Adaptation of the Cambridge Pulmonary Hypertension Outcome Review (CAMPHOR) into French-Canadian and English-Canadian
}

\author{
Donna Coffin $\mathrm{MSc}^{1}$, Karine Duval MSc${ }^{2}$, Simon Martel MD², John Granton MD ${ }^{3}$, Marie-Claude Lefebvre $\mathrm{MSc}^{1}$,
} David M Meads MSc ${ }^{4}$, James Twiss $\mathrm{BSc}^{4}$, Stephen P McKenna $\mathrm{PhD}^{4}$

\begin{abstract}
D Coffin, K Duval, S Martel, et al. Adaptation of the Cambridge Pulmonary Hypertension Outcome Review (CAMPHOR) into French-Canadian and English-Canadian. Can Respir J 2008;15(2):77-83.
\end{abstract}

BACKGROUND: The Cambridge Pulmonary Hypertension Outcome Review (CAMPHOR) is the first disease-specific instrument for assessing patient-reported symptoms, functioning and quality of life (QoL) in pulmonary arterial hypertension (PAH).

OBJECTIVES: To create and validate French-Canadian (FC) and English-Canadian (EC) language versions of the CAMPHOR.

METHODS: A translation panel (for the FC version) and lay panels (for both versions) were convened to adapt the questionnaires (dualpanel methodology). Subsequently, these new questionnaires were field-tested in 15 FC PAH and 15 EC PAH patients. Finally, in a postal validation study, the new language versions of the CAMPHOR underwent psychometric evaluation in $41 \mathrm{FC}$ and $52 \mathrm{EC} \mathrm{PAH} \mathrm{patients} \mathrm{to}$ test for reliability and validity.

RESULTS: The FC and EC field-test interview participants found the questionnaires relevant, comprehensible and easy to complete. Psychometric analyses showed that the FC and EC adaptations were successful. High test-retest coefficients for the scales after controlling for change in respondent's QoL (FC: 0.92 to 0.96; EC: 0.85 to 0.99 ) indicated a high degree of reliability. The FC and EC CAMPHOR scales had good internal consistency (Cronbach's alpha coefficients 0.90 to 0.92 and 0.88 to 0.92 , respectively). Predicted correlations with the Nottingham Health Profile provided evidence of the construct validity of the FC and EC scales. The FC and EC adaptations also showed known groups validity.

CONCLUSIONS: The FC and EC adaptations of the CAMPHOR have been shown to be reliable and valid for measures of healthrelated QoL and QoL in PAH, and thus can be recommended for use in clinical studies and routine practice in $\mathrm{PAH}$.

Key Words: Adaptation; Health status; Pulmonary arterial hypertension; Quality of life; Questionnaire; Validity

$\mathrm{P}$ ulmonary arterial hypertension (PAH) is defined as a group of diseases characterized by a progressive increase of pulmonary vascular resistance leading to right ventricular failure (1). Life expectancy from the time of diagnosis is usually dramatically shortened; for example, in patients with the idiopathic form, life expectancy was only 2.8 years before the availability of disease-specific therapy (2). In the initial stages, symptoms such as exertional dyspnea and intolerance, fatigue,

\section{Adaptation du questionnaire CAMPHOR en français et en anglais pour le Canada}

HISTORIQUE : Le questionnaire CAMPHOR (pour Cambridge Pulmonary Hypertension Outcome Review) est le premier instrument spécifique à une maladie qui permet l'évaluation des symptômes, du fonctionnement et de la qualité de vie déclarés par les patients qui souffrent d'hypertension artérielle pulmonaire (HAP).

OBJECTIF : Créer et valider des versions du questionnaire CAMPHOR en français et en anglais pour le marché canadien.

MÉTHODES : Un comité de traduction (pour la version française) et des comités de citoyens ordinaires (pour les deux versions) ont été formés pour adapter les questionnaires (méthodologie par double comité). Par la suite, les nouveaux questionnaires ont été testés sur le terrain auprès de patients atteints d'HAP, 15, de langue française et 15, de langue anglaise. Finalement, lors d'une étude de validation postale, les nouvelles versions du questionnaire CAMPHOR ont subi une évaluation psychométrique auprès de 41 patients atteints d'HAP de langue française et 52 de langue anglaise pour vérifier la fiabilité et la validité de l'outil.

RÉSULTATS : Les sujets de langue anglaise et française interrogés sur le terrain ont trouvé les questionnaires pertinents, compréhensibles et faciles à compléter. Les analyses psychométriques ont montré que les adaptations en français et en anglais étaient réussies. Les coefficients testretest élevés obtenus avec les échelles de mesure, après contrôle pour tenir compte de la qualité de vie des répondants (en français 0,92 à 0,96, en anglais 0,85 à 0,99 ) ont révélé un fort degré de fiabilité. Les échelles CAMPHOR en français et en anglais ont présenté une bonne cohérence interne (coefficient alpha de Cronbach, 0,90 à 0,92 et 0,88 à 0,92 , respectivement). Les corrélations prévues avec le profil de Nottingham ont fourni les preuves de la validité du concept des échelles en langue française et anglaise. Les adaptations en langue française et anglaise ont aussi témoigné de la validité selon la méthode des groupes connus.

CONCLUSION : Les adaptations en langue française et anglaise du questionnaire CAMPHOR se sont révélées fiables et valides pour mesurer la qualité de vie liée à la santé et la qualité de vie en présence d'HAP et peuvent ainsi être recommandées, tant pour la réalisation d'études cliniques que pour la pratique médicale.

${ }^{1}$ Actelion Pharmaceuticals Canada Inc, Laval; ${ }^{2}$ Hôpital Laval, Sainte-Foy, Quebec; ${ }^{3}$ University of Toronto, Toronto, Ontario; ${ }^{4}$ Galen Research, Manchester, United Kingdom

Correspondence and reprints: Ms Donna Coffin, Actelion Pharmaceuticals Canada Inc, 2550 Daniel-Johnson Boulevard, Suite 701, Laval,

Quebec H7T 2L1. Telephone 450-680-2155, fax 450-681-9545, e-mail donna.coffin@actelion.com 


\begin{tabular}{|c|c|c|c|c|c|}
\hline & $\begin{array}{l}\text { Step 1: Translation } \\
\text { and adaptation }\end{array}$ & $\begin{array}{l}\text { Step 2: } \\
\text { Lay panels }\end{array}$ & $\begin{array}{l}\text { Step 3: Field testing } \\
\text { with PAH patients }\end{array}$ & $\begin{array}{l}\text { Step 4: Psychometric } \\
\text { testing in repeated } \\
\text { postal surveys }\end{array}$ & Step 5: Evaluation \\
\hline $\begin{array}{l}\text { French-Canadian } \\
\text { version }\end{array}$ & $\begin{array}{l}\text { Translation panel } \\
(\mathrm{FC}, \mathrm{n}=6)\end{array}$ & $\begin{array}{l}\text { Lay panel } \\
(\mathrm{FC}, \mathrm{n}=6)\end{array}$ & $\rightarrow \quad \begin{array}{l}\text { Interviews } \\
(\mathrm{FC}, \mathrm{n}=15)\end{array}$ & $\rightarrow \begin{array}{l}\text { Postal surveys (repeat) } \\
(\mathrm{FC}, \mathrm{n}=41)\end{array}$ & $\rightarrow \begin{array}{l}\text { Reliability, internal } \\
\text { consistency, validity }\end{array}$ \\
\hline $\begin{array}{l}\text { English-Canadian } \\
\text { version }\end{array}$ & & $\begin{array}{l}\text { Lay panel } \\
(\mathrm{EC}, \mathrm{n}=6)\end{array}$ & $\rightarrow \quad \begin{array}{l}\text { Interviews } \\
(\mathrm{EC}, \mathrm{n}=15)\end{array}$ & $\rightarrow \begin{array}{l}\text { Postal surveys (repeat) } \\
(\mathrm{EC}, \mathrm{n}=52)\end{array}$ & $\rightarrow \begin{array}{l}\text { Reliability, internal } \\
\text { consistency, validity }\end{array}$ \\
\hline
\end{tabular}

Figure 1) Study flow adaptation and testing of the Cambridge Pulmonary Hypertension Outcome Review language versions. EC English-Canadian; FC French-Canadian; PAH Pulmonary arterial hypertension

have a higher sensitivity to change following treatment, compared with generic HRQoL assessments, are needed. The Cambridge Pulmonary Hypertension Outcome Review (CAMPHOR) is such a disease-specific measure that was designed to assess both HRQoL (symptoms and functioning) and QoL in people diagnosed with PAH (5). It is an evaluation tool designed for use in clinical trials and clinical practice. It is a validated discriminative tool, able to distinguish between patients based on ratings of their self-perceived health and on their New York Heart Association classification. It is also a validated evaluation tool with the ability to evaluate the symptoms, physical functioning and QoL of patients with PAH. The QoL questionnaire was developed using the needs-based model (6), which has been used successfully in the development of several disease-specific QoL instruments (7-10). It is based on the premise that life gains its quality from the ability of the individual to satisfy his needs. Consequently, QoL is highest when most needs are met, and disease influences QoL only insofar as it limits need fulfilment. The CAMPHOR scales, originally developed for use in the United Kingdom (UK), consist of a 25-item overall symptoms scale with three subscales (energy, breathlessness, mood), a 15-item functioning scale and a 25-item QoL scale (5). The scales were found to have good internal consistency (Cronbach's alpha 0.90 to 0.92 ) and reproducibility (test-retest correlations 0.86 to 0.92 ). The scales of the CAMPHOR were also found to exhibit adequate convergent, divergent and known groups validity (5).

The present paper describes the official adaptation of the CAMPHOR for use in Canada. French-Canadian (FC) and English-Canadian (EC) language and cultural adaptations were developed, which are conceptually equivalent to the original UK English version.

A translation panel (for the FC version) and lay panels (for both language versions) were convened to adapt the questionnaire. The adapted questionnaires were then field tested and amended accordingly. Finally, the new language versions of the CAMPHOR underwent psychometric evaluation to test for reliability and validity.

\section{METHODS}

The adaptation of the CAMPHOR questionnaire involved a multistep procedure: translation, field-testing and testing for reliability, internal consistency and validity (Figure 1). Ethics committee approval was obtained from each participating centre.

Step 1: Bilingual translation process for the $\mathrm{FC}$ version The bilingual panel involved a group of six FCs with good competence in both English and French who had the latter as their primary language. They were asked to read the UK
CAMPHOR with a view to translating, with the following requirements in mind: capturing the same concepts as the UK English version, and producing a comprehensible and acceptable formulation of the concepts. Each item was discussed until agreement was reached on an appropriate translation, always striving to keep the language as simple as possible. When consensus was not reached, alternative versions of the item were taken forward for consideration by the lay panel.

\section{Step 2: Lay panels}

A separate lay panel of six nonbilingual participants was conducted for each of the two language versions to ensure that the wording of the items was appropriate. Participants in the French panel were presented with the translations made by the bilingual panel, and participants in the English panel were presented with the original UK version. The panels were asked to comment on the items in terms of comprehension, acceptability and whether they sounded 'natural'. The French panel was also asked to choose between any alternative translations that the bilingual panel had produced.

\section{Step 3: Field test interviews}

The purpose of these one-to-one semistructured interviews with PAH patients was to test the face and content validity (applicability, comprehension, relevance and comprehensiveness) of the new versions of the questionnaire. For the FC version, 15 patients were recruited via a clinician at the pulmonary hypertension clinic at Laval Hospital (Sainte-Foy, Quebec); for the EC version, 15 further patients were recruited at the pulmonary hypertension clinic at the Toronto General Hospital (Toronto, Ontario). Fifteen patients per group was determined to be a sufficient number of patients to assess the content validity of the questionnaire in the event that no major problems were detected. There was the possibility of increasing the sample size if major problems with the content of the $\mathrm{EC}$ or $\mathrm{FC}$ questionnaire were observed. Participants were required to be 18 years of age or older with an established diagnosis of pulmonary hypertension according to the World Health Organization diagnostic classification: PAH or pulmonary hypertension due to chronic thromboembolic pulmonary hypertension. Subjects were also required to be active patients at one of the two participating PAH clinics. Exclusion criteria included patients who had undergone a pulmonary thromboendarterectomy and patients who, in the opinion of the physician, were unable to understand what was required of them or whose circumstances may have led to unacceptable distress during the interview. The English version of CAMPHOR was completed by EC speaking patients and the French version by FC speaking patients. 
Interviewees completed the questionnaire and were then asked to comment on whether they believed the items were relevant, applicable and comprehensible, and whether they believed any important aspects of their experience of PAH had been omitted.

\section{Step 4: Psychometric testing in repeated postal surveys} To establish the psychometric properties of the FC and EC language versions of the CAMPHOR, responses to the scales were collected from 41 FC and 52 EC PAH patients. Sample size was restricted by the rarity of this condition; therefore, the lowest possible number of patients that would give a reliable estimate of the test-retest reliability and construct validity was considered. The recipients of the postal survey included male or female subjects who were 18 years of age or older with an established diagnosis of PAH or chronic thromboembolic pulmonary hypertension according to the World Health Organization diagnostic classification. Subjects were active patients at one of the two participating PAH clinics and received the questionnaires that were in their primary language (ie, either French or English). Exclusion criteria omitted patients who had undergone a pulmonary thromboendarterectomy and patients who, in the opinion of the physician, were unable to understand what was required of them. Both the FC and the EC versions of the CAMPHOR were administered on two occasions by mail approximately two weeks apart. Participants also completed the Nottingham Health Profile (NHP) on both occasions. The latter questionnaire is a generic measure of perceived distress consisting of 38 items in six subscales (energy level, pain, emotional reactions, sleep, social isolation and physical mobility) (11). Furthermore, on the first test administration, questions about demography (sex, age, marital status, occupation) and patients' current condition (time since diagnosis, duration of symptoms, oxygen use and their perceived general health) were asked.

\section{Step 5: Evaluation of test-retest reliability, internal consis-} tency and construct validity

Internal consistency of the CAMPHOR adaptations was evaluated by determining the Cronbach's alpha coefficients (for the subscales and for the total questionnaire). The relatedness of individual items to the overall score was also assessed using the corrected item-total correlation coefficients. Test-retest reliability (patient-specific agreement between repeated administrations) was examined using Spearman's rank correlations. Construct validity was assessed with the NHP as comparator. Known groups validity (ability to distinguish between groups of patients who differ according to some known factor) was tested for the factors 'participants' general health' (very good/good versus fair/poor), oxygen use (yes versus no) and 'time since diagnosis' (above versus below the median of the sample).

With the exception of Cronbach's alpha, nonparametric tests for independent samples (Mann-Whitney U Test) were used throughout the analyses because of the ordinal nature of the measures.

\section{FC bilingual panel}

\section{RESULTS}

Most of the translation process proved straightforward with agreement reached with little discussion. However, some item translations required more extensive discussion. For example, the expression "My stamina levels are low" (item 1, symptoms) led to discussion about whether to use énergie (energy) or endurance.

\section{FC and EC lay panels}

Most of the content proved relatively straightforward, with agreement reached with little discussion. However, some alternative words or sentences were proposed, because they were considered more appropriate and easier to understand by the groups. For example, the FC panel changed item 22 in symptoms "Je ne m'amuse plus" (I don't enjoy myself anymore) to "Je n'ai plus de plaisir" (I do not have pleasure anymore). For the EC version, 17 of the 65 questions of the UK version were slightly adapted. For example, "I get breathless when I bend over" was adapted as "I become short of breath when I bend over", and "I get very down" was adapted as "Emotionally, I get very down".

The level of difficulty of reading the EC version was assessed using the Flesch-Kincaid Grade Level evaluation tool designed only for English reports. The final reading level was at a 7.3 grade level, indicating that the EC version is understandable to a person with at least a grade 7 education.

\section{Field testing}

Interviews: The demographic and disease characteristics of the FC and EC samples for interviews (15 patients each) are summarized in Table 1.

The mean time taken to complete the FC questionnaire was $10.7 \mathrm{~min}$ (range $5 \mathrm{~min}$ to $15 \mathrm{~min}$ ) and $20.7 \mathrm{~min}$ (range $8 \mathrm{~min}$ to $55 \mathrm{~min}$ ) for the EC questionnaire. Generally, the instructions and the purpose of the interviews were well understood by most patients. The items were clear and easy to understand, and participants found the questionnaire to be representative of the patients' experience. No items were skipped or missed.

Postal surveys: A majority of the participants in both samples were women, as well as married or living as married. Over onehalf of the participants in the FC survey were unable to work, while nearly all of the participants in the EC survey were currently unable to work (Table 1 ).

Table 2 contains data regarding the descriptive scores of the FC and the EC adaptations at administration time 1 (ie, the first postal survey) (time 2 data not shown). Scores were relatively similar across administrations, providing evidence of the stability and reliability of the instruments.

\section{Test-retest reliability}

The mean time between repeated postal administrations was 18.2 days (median 14 days, $\mathrm{n}=41$ ) for the $\mathrm{FC}$ version and 28.7 days (median 23 days, $n=47$ ) for the $E C$ version.

Details of the FC and EC test-retest reliability are shown in Table 3. Test-retest analyses were conducted for the functioning and symptom scales after controlling for change in respondent's QoL between the two test dates. Cases were excluded if more than $10 \%$ change in CAMPHOR QoL scale scores was found between the administrations. For the QoL scale, a 10\% change limit in the functioning scale score was applied, so only patients whose functioning scores had not changed by more than $10 \%$ between administrations were included in the QoL scale test-retest calculation. This was to ensure that the cases with marked changes in functioning between tests were excluded. It is likely that such 
TABLE 1

Field test of the French-Canadian (FC) and English-Canadian (EC) Cambridge Pulmonary Hypertension Outcome Review adaptations: Demographics and disease characteristics of respondents

\begin{tabular}{|c|c|c|c|c|}
\hline \multirow[b]{2}{*}{ Characteristic } & \multicolumn{2}{|c|}{ Interviews } & \multicolumn{2}{|c|}{ Postal survey } \\
\hline & $F C(n=15)$ & $E C(n=15)$ & $F C(n=41)$ & $E C(n=52)$ \\
\hline \multicolumn{5}{|l|}{ Sex, n (\%) } \\
\hline Women & $12(80.0)$ & $14(93.0)$ & $32(78.0)$ & $40(76.9)$ \\
\hline Age, years, mean $\pm S D$ & $54.9 \pm 12.4$ & $41 \pm 16.1$ & $54.4 \pm 15.6$ & $54.8 \pm 17.08$ \\
\hline \multicolumn{5}{|l|}{ Marital status, n (\%) } \\
\hline Married/living as married & $9(60.0)$ & $9(60.0)$ & $28(68.3)$ & $37(71.2)$ \\
\hline Single & $6(40.0)$ & $6(40.0)$ & $13(31.7)$ & $15(28.8)$ \\
\hline \multicolumn{5}{|l|}{ Employment status, n (\%) } \\
\hline Able to work & $6(40.0)$ & $9(60.0)$ & $17(41.5)$ & $5(9.6)$ \\
\hline Unable to work & $9(60.0)$ & $4(26.7)$ & $24(58.5)$ & $47(90.4)$ \\
\hline Data missing & - & $2(13.3)$ & - & - \\
\hline \multicolumn{5}{|l|}{ Duration of illness, years } \\
\hline Mean \pm SD & $5.9 \pm 9.1$ & $2.1 \pm 1.6$ & $7.6 \pm 17.4$ & $6.5 \pm 9.4$ \\
\hline Median (interquartile range) & $3.0(1.0-6.0)$ & $2.0(0.6-3.2)$ & $2.5(0.5-5.0)$ & $3.5(2.5-6.0)$ \\
\hline Range & $0.0-37.0$ & $0.0-5.7$ & $0.0-46$ & $0.7-47.0$ \\
\hline Data missing, n (\%) & - & $2(13.3)$ & - & $1(1.9)$ \\
\hline \multicolumn{5}{|l|}{ Oxygen use, n (\%) } \\
\hline Yes & $2(13.3)$ & $5(33.3)$ & $19(46.3)$ & $13(25.0)$ \\
\hline No & $13(86.7)$ & $10(66.7)$ & $22(53.7)$ & $39(75.0)$ \\
\hline \multicolumn{5}{|l|}{ Patient general health, n (\%) } \\
\hline Very good & $2(13.3)$ & $1(6.7)$ & $3(7.3)$ & $2(3.8)$ \\
\hline Good & $4(27.6)$ & $7(46.7)$ & $12(29.3)$ & $15(28.8)$ \\
\hline Fair & $7(46.7)$ & $6(40.0)$ & $22(53.7)$ & $27(51.9)$ \\
\hline Poor & $2(13.3)$ & $1(6.7)$ & $4(9.8)$ & $8(15.5)$ \\
\hline
\end{tabular}

TABLE 2

Descriptive scores for the outcome measures in the French-Canadian and English-Canadian Cambridge Pulmonary Hypertension Outcome Review adaptations

\begin{tabular}{|c|c|c|c|c|c|c|}
\hline French-Canadian version & $\mathbf{n}$ & Median (IQR) & Mean \pm SD & Score range & $\begin{array}{c}\text { Per cent } \\
\text { scoring minimum }\end{array}$ & $\begin{array}{c}\text { Per cent } \\
\text { scoring maximum }\end{array}$ \\
\hline Quality of life score & 41 & $9.1(4.0-13.5)$ & $10.4 \pm 5.6$ & $0-22$ & 4.9 & 0.0 \\
\hline Functioning score & 41 & $11.0(6.0-14.5)$ & $11.0 \pm 6.0$ & $0-23$ & 2.4 & 0.0 \\
\hline Symptoms total score & 41 & $10.0(5.5-14.0)$ & $10.4 \pm 6.2$ & $1-25$ & 0.0 & 4.9 \\
\hline Energy scale & 41 & $4.0(2-7)$ & $4.4 \pm 3.0$ & $0-10$ & 9.8 & 7.3 \\
\hline Breathlessness scale & 41 & $4.0(2-5)$ & $4.0 \pm 2.1$ & $0-8$ & 4.9 & 4.9 \\
\hline Mood scale & 41 & $1.0(0-5)$ & $2.1 \pm 2.2$ & $0-7$ & 31.7 & 7.3 \\
\hline English-Canadian version & $\mathbf{n}$ & Median (IQR) & Mean \pm SD & Score range & $\begin{array}{c}\text { Per cent } \\
\text { scoring minimum }\end{array}$ & $\begin{array}{c}\text { Per cent } \\
\text { scoring maximum }\end{array}$ \\
\hline Quality of life score & 50 & $9.0(6.0-16.8)$ & $10.3 \pm 6.9$ & $0-24$ & 5.8 & 0.0 \\
\hline Functioning score & 50 & $10.5(6-12.3)$ & $10.6 \pm 6.1$ & $0-26$ & 2.0 & 0.0 \\
\hline Symptoms total score & 52 & $11.0(8.0-16.0)$ & $11.4 \pm 5.6$ & $0-23$ & 3.8 & 0.0 \\
\hline Energy scale & 52 & $5.0(3.0-9.0)$ & $5.4 \pm 3.3$ & $0-10$ & 7.7 & 17.3 \\
\hline Breathlessness scale & 52 & $3.0(3.0-4.0)$ & $3.5 \pm 1.8$ & $0-8$ & 5.8 & 5.8 \\
\hline Mood scale & 52 & $2.0(1.0-4.0)$ & $2.5 \pm 2.2$ & $0-7$ & 21.6 & 9.8 \\
\hline
\end{tabular}

Descriptive statistics at administration time 1 are shown for French-Canadian and English-Canadian adaptations. Scores are relatively similar across administrations, providing evidence of the stability of the instruments. IQR Interquartile range

cases had experienced a clinically meaningful change in QoL rather than random variation in scores. The test-retest coefficients for both language versions all reached an adequate level of reliability except the EC mood scale (FC: QoL, 0.95; functioning, 0.92; symptoms, 0.96; EC: QoL, 0.99; functioning, 0.85 ; symptoms, 0.85$)$. This indicates that there were very low levels of random measurement error within the scales.

Internal consistency

Table 4 gives details of the internal consistency of the FC and EC CAMPHOR adaptations. The Cronbach's alpha coefficients 
TABLE 3

Test-retest reliability of the French-Canadian and EnglishCanadian Cambridge Pulmonary Hypertension Outcome Review adaptations with and without change limits

\begin{tabular}{lcc}
\hline $\begin{array}{l}\text { French-Canadian } \\
\text { version }\end{array}$ & $\begin{array}{c}\text { Reliability coefficient } \\
\text { without change limits } \\
(\mathbf{n}=\mathbf{4 1})\end{array}$ & $\begin{array}{c}\text { Reliablility coefficient } \\
\text { with change limits } \\
\text { (n=27) }\end{array}$ \\
\hline Quality of life scale & 0.89 & 0.95 \\
Functioning scale & 0.91 & 0.92 \\
Symptoms total score & 0.91 & 0.96 \\
Energy scale & 0.94 & 0.93 \\
Breathlessness scale & 0.85 & 0.91 \\
Mood scale & 0.79 & 0.87 \\
English-Canadian & without change limits & $\begin{array}{c}\text { Reliablility coefficient } \\
\text { with change limits } \\
\text { (n=27) }\end{array}$ \\
version & $\mathbf{n = 4 7 )}$ & 0.99 \\
Quality of life scale & 0.90 & 0.85 \\
Functioning scale & 0.73 & 0.85 \\
Symptoms total score & 0.75 & 0.90 \\
Energy scale & 0.77 & 0.92 \\
Breathlessness scale & 0.77 & 0.68 \\
Mood scale & 0.64 & \\
\hline
\end{tabular}

ranged from 0.69 to 0.92 , indicating that the instruments have adequate relatedness of items.

\section{Convergent and divergent validity}

Correlation coefficients among the five scales for the FC CAMPHOR at time 1 (Table 5) ranged from 0.31 to 0.92 and for the EC CAMPHOR from 0.17 to 0.87 , with the highest being between the energy scale and symptoms total score for both the EC and FC. All of the scales in the CAMPHOR were found to have a statistically significant relation with each other except the mood and breathlessness scales (at time 1 only for both FC and EC versions).

The statistical analysis between the FC and EC CAMPHOR adaptations and the NHP revealed strong correlations between the CAMPHOR and NHP energy scales, the CAMPHOR mood scales and the NHP emotional reactions scales, and the CAMPHOR functioning scales and the NHP physical mobility scales. This provides evidence of construct validity. Details are shown in Table 6.

\section{Known groups validity}

The known groups validity of the FC and EC CAMPHOR adaptations were assessed by examining the instrument's ability to distinguish between groups of participants that differed according to their perceived overall general health, oxygen use and time since diagnosis.

Most of the FC and EC CAMPHOR subscales were able to distinguish between those individuals whose general health was very good/good versus those whose general health was fair/poor (Figure 2). With the exception of the mood and breathlessness subscales on the FC version, all subscales showed an ability to distinguish appropriately between groups on the basis of self-perceived general health.

Several of the FC and EC CAMPHOR subscales were able to distinguish between participants on the basis of whether or not they had to use oxygen (with the exception of the energy subscale on the $\mathrm{FC}$ version and the mood subscale on the EC and FC versions). Oxygen use was associated with worse
TABLE 4

Internal consistency for the French-Canadian (FC) and English-Canadian (EC) Cambridge Pulmonary Hypertension Outcome Review scales*

\begin{tabular}{lccccc}
\hline \multirow{2}{*}{ Scales } & \multicolumn{2}{c}{ FC version } & & \multicolumn{2}{c}{ EC version } \\
\cline { 2 - 3 } \cline { 6 - 6 } & Time 1 & Time 2 & & Time 1 & Time 2 \\
\hline Quality of life scale & 0.90 & 0.92 & & 0.89 & 0.92 \\
Functioning scale & 0.92 & 0.91 & & 0.92 & 0.90 \\
Symptoms total score & 0.91 & 0.92 & & 0.88 & 0.91 \\
Energy scale & 0.87 & 0.91 & & 0.90 & 0.89 \\
Breathlessness scale & 0.79 & 0.82 & & 0.69 & 0.75 \\
Mood scale & 0.83 & 0.81 & & 0.82 & 0.81 \\
\hline
\end{tabular}

${ }^{*}$ Cronbach's alpha coefficients

symptoms, functioning and QoL (Figure 3) on both the FC and EC versions.

Both language adaptations did not distinguish between those participants who differed according to length of time since diagnosis of PAH.

\section{DISCUSSION}

In the present study, psychometric analyses showed that the FC and EC language and cultural adaptations of the original UK CAMPHOR were successful.

- High test-retest coefficients for the scales after controlling for change indicated excellent reliability with minimal random measurement error.

- The FC and EC CAMPHOR scales had good internal consistency.

- Predicted relations were found between the CAMPHOR and NHP (a generic measure of health status) sections, providing evidence of the construct validity of the FC and EC scales.

- The FC and EC adaptations also demonstrated known groups validity.

Translations that are conceptually equivalent facilitate the comparison of scores across countries more readily than translations focused solely on linguistic equivalence and provide greater justification for the combination of data from different countries in international clinical studies. The objective in adapting questionnaires is to ensure that items are understood in the same way in different countries. It is also important that each item represents a similar level of severity across countries. This translation process adopted the dual-panel methodology recommended by Hunt et al (6), which emphasizes the importance of achieving conceptual equivalence of translated items to the original. The dualpanel methodology has been successfully used for a number of other QoL questionnaire adaptations, eg, the rheumatoid arthritis QoL scale for use in Sweden (12) and Canada (13), and the Stanford Health Assessment Questionnaire (14). It is not always possible to find a 'natural' translation for an item in a new language or where it is possible, it may be interpreted differently in the local culture. When this is the case, it is necessary to find a phrase that describes an equivalent concept. Linguistic equivalence is of secondary importance in this methodology. In addition, it is vital that the new items be expressed in common (everyday) language, so that they will appeal to future respondents. Therefore, this 
TABLE 5

Scale correlations for the French-Canadian and English-Canadian Cambridge Pulmonary Hypertension Outcome Review adaptations

\begin{tabular}{|c|c|c|c|c|c|c|}
\hline $\begin{array}{l}\text { French-Canadian } \\
\text { version }\end{array}$ & $\begin{array}{l}\text { Quality of life } \\
\text { score }\end{array}$ & $\begin{array}{l}\text { Functioning } \\
\text { score }\end{array}$ & $\begin{array}{l}\text { Symptoms total } \\
\text { score }\end{array}$ & $\begin{array}{l}\text { Energy } \\
\text { scale }\end{array}$ & $\begin{array}{c}\text { Breathlessness } \\
\text { scale }\end{array}$ & $\begin{array}{l}\text { Mood } \\
\text { scale }\end{array}$ \\
\hline QoL score & 1.00 & & & & & \\
\hline Functioning score & $0.72^{* *}$ & 1.00 & & & & \\
\hline Symptoms total score & $0.66^{* *}$ & $0.77^{* *}$ & 1.00 & & & \\
\hline Energy scale & $0.52^{* *}$ & $0.68^{* *}$ & $0.92^{* *}$ & 1.00 & & \\
\hline Breathlessness scale & $0.48^{* *}$ & $0.68^{* *}$ & $0.80 * *$ & $0.67^{\star *}$ & 1.00 & \\
\hline Mood scale & $0.68^{* *}$ & $0.48^{* *}$ & $0.69^{* *}$ & $0.53^{* *}$ & 0.31 & 1.00 \\
\hline $\begin{array}{l}\text { English-Canadian } \\
\text { version }\end{array}$ & $\begin{array}{l}\text { Quality of life } \\
\text { score }\end{array}$ & $\begin{array}{l}\text { Functioning } \\
\text { score }\end{array}$ & $\begin{array}{l}\text { Symptoms total } \\
\text { score }\end{array}$ & $\begin{array}{l}\text { Energy } \\
\text { scale }\end{array}$ & $\begin{array}{l}\text { Breathlessness } \\
\text { scale }\end{array}$ & $\begin{array}{l}\text { Mood } \\
\text { scale }\end{array}$ \\
\hline QoL score & 1.00 & & & & & \\
\hline Functioning score & $0.82^{* *}$ & 1.00 & & & & \\
\hline Symptoms total score & $0.78^{\star *}$ & $0.79^{* *}$ & 1.00 & & & \\
\hline Energy scale & $0.69^{* *}$ & $0.68^{* *}$ & $0.87^{* *}$ & 1.00 & & \\
\hline Breathlessness scale & $0.50^{* *}$ & $0.64^{* *}$ & $0.66^{\star *}$ & $0.55^{\star *}$ & 1.00 & \\
\hline Mood scale & $0.65^{* *}$ & $0.56^{\star *}$ & $0.66^{* *}$ & $0.33^{* *}$ & 0.17 & 1.00 \\
\hline
\end{tabular}

The data presented are correlation coefficients at time 1. ${ }^{* *} P<0.001$

TABLE 6

Correlations of the Cambridge Pulmonary Hypertension Outcome Review (CAMPHOR) language adaptations with Nottingham Health Profile sections

\begin{tabular}{|c|c|c|c|c|c|c|}
\hline \multirow[b]{2}{*}{ French-Canadian version } & \multicolumn{5}{|c|}{ Nottingham Health Profile } & \multirow[b]{2}{*}{ Physical mobility } \\
\hline & Energy level & Pain & Emotional reactions & Sleep & Social isolation & \\
\hline CAMPHOR QoL score & $0.66^{\star *}$ & $0.36^{*}$ & $0.59^{* *}$ & $0.36^{*}$ & $0.65^{* *}$ & $0.60^{\star *}$ \\
\hline CAMPHOR functioning score & $0.73^{\star *}$ & $0.56^{* *}$ & $0.43^{\star *}$ & 0.26 & $0.49^{* *}$ & $0.82^{* *}$ \\
\hline CAMPHOR symptoms total score & $0.88^{* *}$ & $0.49^{* *}$ & $0.64^{\star \star}$ & $0.56^{\star *}$ & $0.39^{*}$ & $0.85^{\star *}$ \\
\hline CAMPHOR energy scale & $0.88^{* *}$ & $0.44^{* *}$ & $0.57^{* *}$ & $0.52^{* *}$ & 0.30 & $0.83^{* *}$ \\
\hline CAMPHOR breathlessness scale & $0.68^{* *}$ & $0.45^{\star *}$ & 0.28 & $0.37^{*}$ & 0.28 & $0.72^{* *}$ \\
\hline \multirow[t]{2}{*}{ CAMPHOR mood scale } & $0.54^{* *}$ & 0.25 & $0.80^{* *}$ & $0.51^{* *}$ & $0.36^{*}$ & $0.41^{* *}$ \\
\hline & \multicolumn{6}{|c|}{ Nottingham Health Profile } \\
\hline English-Canadian version & Energy level & Pain & Emotional reactions & Sleep & Social isolation & Physical mobility \\
\hline CAMPHOR QoL score & $0.63^{* *}$ & $0.35^{\star}$ & $0.75^{\star *}$ & $0.37^{\star *}$ & $0.72^{\star \star}$ & $0.79^{\star *}$ \\
\hline CAMPHOR functioning score & $0.60^{* *}$ & $0.56^{\star *}$ & $0.65^{\star *}$ & 0.28 & $0.62^{\star *}$ & $0.88^{\star *}$ \\
\hline CAMPHOR symptoms total score & $0.78^{* *}$ & 0.25 & $0.63^{* *}$ & $0.28^{*}$ & $0.56^{\star *}$ & $0.70^{* \star}$ \\
\hline CAMPHOR energy scale & $0.87^{* *}$ & 0.27 & $0.47^{* *}$ & 0.22 & $0.47^{* *}$ & $0.65^{\star \star}$ \\
\hline CAMPHOR breathlessness scale & $0.52^{\star \star}$ & 0.24 & $0.42^{* *}$ & 0.19 & 0.27 & $0.58^{\star \star}$ \\
\hline CAMPHOR mood scale & $0.32^{*}$ & 0.16 & $0.62^{\star \star}$ & $0.37^{\star \star}$ & $0.56^{\star *}$ & $0.50^{* *}$ \\
\hline
\end{tabular}

${ }^{*} P<0.05 ;{ }^{* *} P<0.001$. QoL Quality of life

method of translation does not involve back-translation, because the latter has been shown to be inefficient and often produces poor results (15).

According to the psychometric analyses, the translations and adaptations had good internal consistency and test-retest reliability. The EC version was based on a sample of Canadians who had English as their first language and who came from the same province. It was believed that this sample of patients would be representative of all Canadians who have English as their first language. However, because all subjects originated from the same province, it is possible that their Canadian-English language and/or vocabulary was not representative of Canadians from all provinces that have English as their first language. This will be investigated in future studies. High test-retest correlations for both the FC and EC scales indicated a high degree of reliability and minimal random measurement error after controlling for change in a patient's status over time. The length of time between the two administrations was longer than ideal, particularly for the EC version (mean of 28 days in the $\mathrm{EC}$ version and 18 days in the $\mathrm{FC}$ version, compared with the standard period of 14 days). It is not unusual for a proportion of participants with severe conditions to take a long time to reply to a questionnaire due to their condition. It was noted that several patients who were delayed in returning their second questionnaire reported being hospitalized during this period, resulting in the delay. The longer time delay allowed for too great a change in patient's status to occur between the two administrations, resulting in lower test-retest correlations. Controlling for change in patient's status over time helped overcome this problem, with only the mood symptom subscale for the EC adaptation failing to meet the required level of reliability. The 


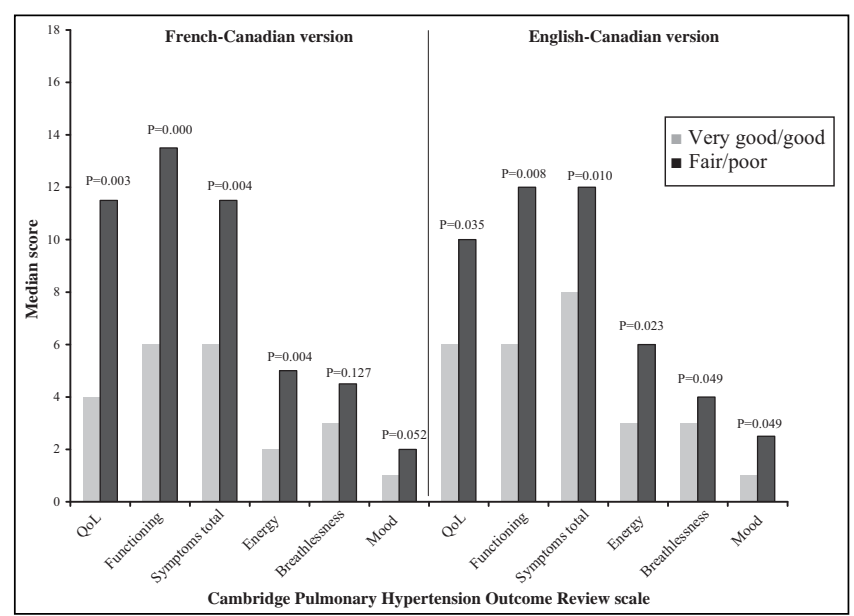

Figure 2) French-Canadian and English-Canadian known groups validity for self-perceived general health (very good/good versus fair/poor) at time 1. QoL Quality of life

inability of the mood scale to show the appropriate level of reliability may be attributable to the relatively small sample size used. Despite this, the overall symptoms scale did exhibit good psychometric properties.

The internal consistency of the measure was confirmed for both language adaptations, with evidence that the items were adequately inter-related. The correlations with the NHP were as expected, providing evidence of convergent validity. The scales assessing similar factors on the NHP and the CAMPHOR had strong associations with each other, indicating that they are measuring similar constructs.

Both the FC and EC adaptations of the CAMPHOR were able to distinguish between groups on the basis of general health, with higher scores on the CAMPHOR (indicating worse HRQoL and QoL) for those individuals with fair/poor general health compared with those with very good/good general health. The CAMPHOR was also able to distinguish between participants on the basis of whether or not they were currently using oxygen.

\section{REFERENCES}

1. Galiè N, Torbicki A, Barst R, et al. Guidelines on diagnosis and treatment of pulmonary arterial hypertension. The Task Force on Diagnosis and Treatment of Pulmonary Arterial Hypertension of the European Society of Cardiology. Eur Heart J 2004;25:2243-78

2. D'Alonzo GE, Barst RJ, Ayres SM, et al. Survival in patients with primary pulmonary hypertension. Results from a national prospective registry. Ann Intern Med 1991;115:343-9.

3. Barst RJ, McGoon M, Torbicki A, et al. Diagnosis and differential assessment of pulmonary arterial hypertension. J Am Coll Cardiol 2004;43(Suppl S):40S-7S

4. Badesch DB, Abman SH, Ahearn GS, et al. Medical therapy for pulmonary arterial hypertension: ACCP evidence-based clinical practice guidelines. Chest 2004;126(1 Suppl):35S-62S.

5. McKenna SP, Doughty N, Meads DM, Doward LC, Pepke-Zaba J. The Cambridge Pulmonary Hypertension Outcome Review (CAMPHOR): A measure of health-related quality of life and quality of life for patients with pulmonary hypertension. Qual Life Res 2006;15:103-15.

6. Hunt SM, McKenna SP. The QLDS: A scale for the measurement of quality of life in depression. Health Policy 1992;22:307-19.

7. McKenna SP, Doward LC, Kohlmann T, et al. International development of the Quality of Life in Depression Scale (QLDS). J Affect Disord 2001;63:189-99.

8. Doward LC, Spoorenberg A, Cook SA, et al. Development of the ASQoL: A quality of life instrument specific to ankylosing spondylitis. Ann Rheum Dis 2003;62:20-6.

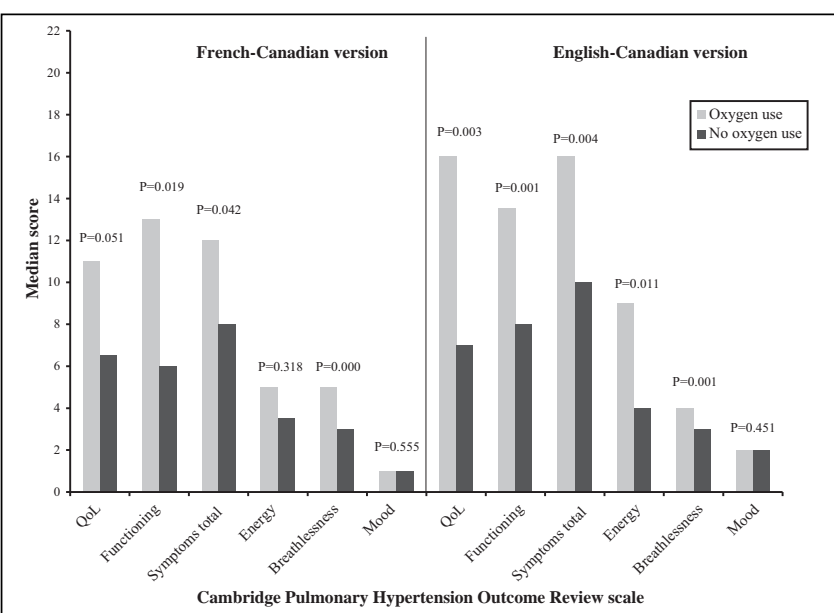

Figure 3) FC and EC known groups validity for oxygen use (yes versus no) at time 1. QoL Quality of life

\section{CONCLUSIONS}

The results of the present study indicate that the newly developed FC and EC versions of the CAMPHOR compare well to the original UK version. Both new instruments represent valid and reliable tools for measuring HRQoL in Canadian patients with PAH.

ACKNOWLEDGEMENT: This study was conducted under a contract from Actelion Pharmaceuticals Ltd, Canada.

CONFLICTS OF INTEREST: Donna Coffin is an employee of Actelion Pharmaceuticals Canada Inc; Karine Duval has no financial or other potential conflicts of interest; Dr Simon Martel has no financial or other potential conflicts of interest; Dr John Granton has received fees for consulting and speaking, as well as research funds from Actelion Pharmaceuticals Canada; MarieClaude Lefebvre is an employee of Actelion Pharmaceuticals Canada Inc; David M Meads has been a paid consultant for Actelion Pharmaceuticals Canada; James Twiss has no financial or other potential conflicts of interest; and Stephen P McKenna has been a paid consultant for Actelion Pharmaceuticals Canada.

9. McKenna SP, Doward LC, Whalley D, Tennant A, Emery P, Veale DJ. Development of the PsAQoL: A quality of life instrument specific to psoriatic arthritis. Ann Rheum Dis 2004;63:162-9.

10. Whalley D, McKenna SP, Dewar AL, et al. A new instrument for assessing quality of life in atopic dermatitis: International development of the Quality of Life Index for Atopic Dermatitis (QoLIAD). Br J Dermatol 2004; 150:274-83

11. Hunt S, McEwen J, McKenna S. Measuring Health Status. London: Croom Helm, 1986.

12. Hedin PJ, McKenna SP, Meads DM. The Rheumatoid Arthritis Quality of Life (RAQoL) for Sweden: Adaptation and validation. Scand J Rheumatol 2006;35:117-23.

13. Neville C, Whalley D, McKenna S, Le Comte M, Fortin PR. Adaptation and validation of the rheumatoid arthritis quality of life scale for use in Canada. J Rheumatol 2001;28:1505-10.

14. Thorsen H, Hansen TM, McKenna SP, Sørensen SF, Whalley D. Adaptation into Danish of the Stanford Health Assessment Questionnaire (HAQ) and the Rheumatoid Arthritis Quality of Life Scale (RAQoL). Scand J Rheumatol 2001;30:103-9.

15. Leplège A, Verdier A. The adaptation of health status measures: Methodological aspects of the translation procedure. In: Shumaker SA, Berzon R, eds. International Use and Performance of Health-Related Quality of Life Instruments. Oxford: Rapid Communication, 1995.

16. Streiner DL, Norman GR. Health Measurement Scales: A Practical Guide to Their Development and Use. Oxford: Oxford Medical Publications, 1989. 


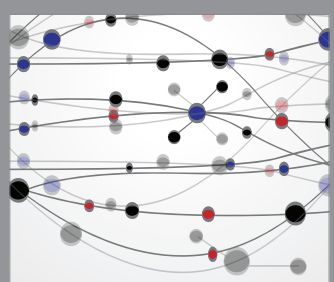

The Scientific World Journal
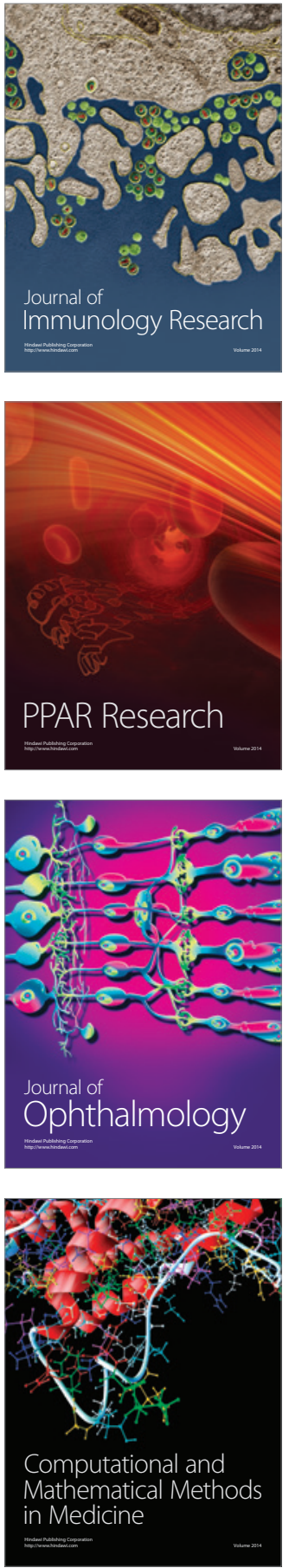

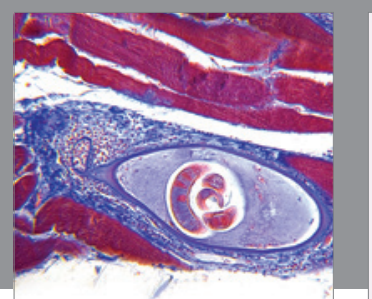

Gastroenterology Research and Practice

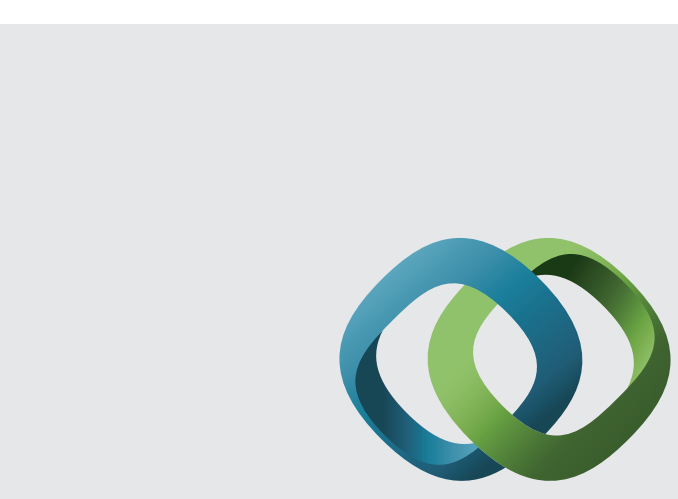

\section{Hindawi}

Submit your manuscripts at

http://www.hindawi.com
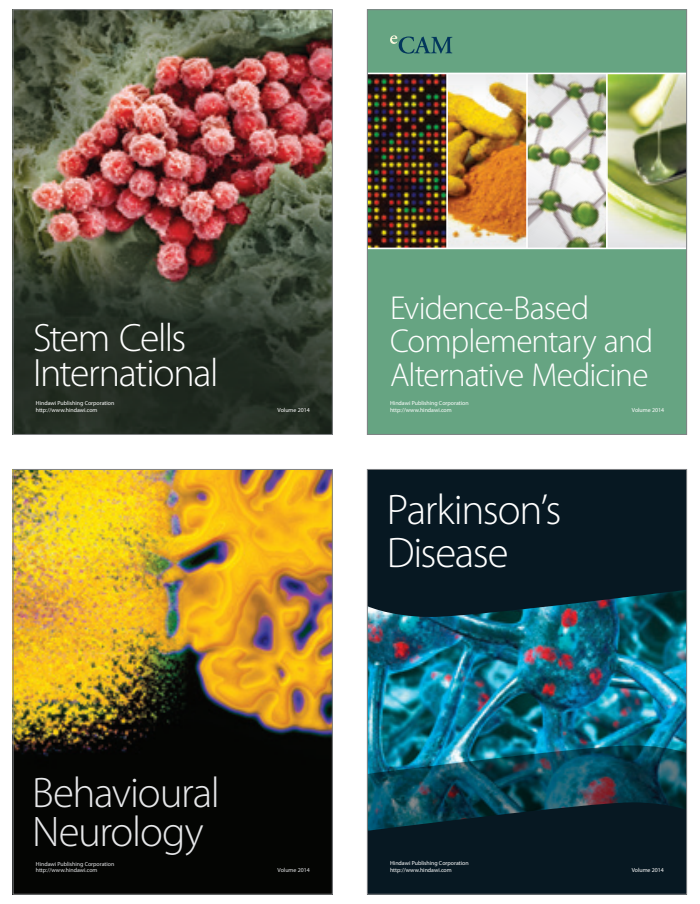
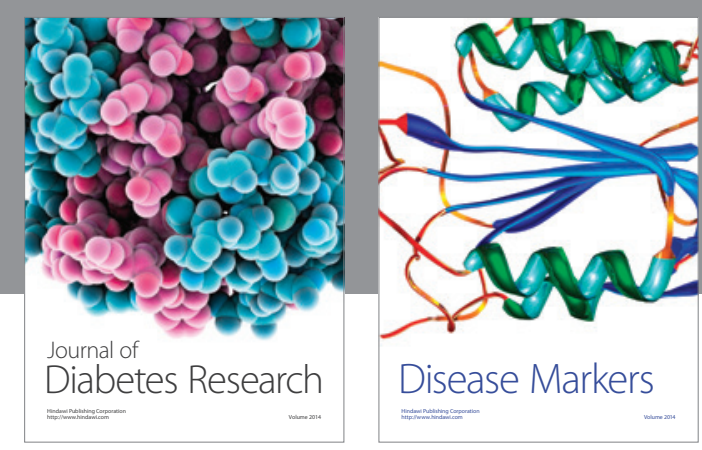

Disease Markers
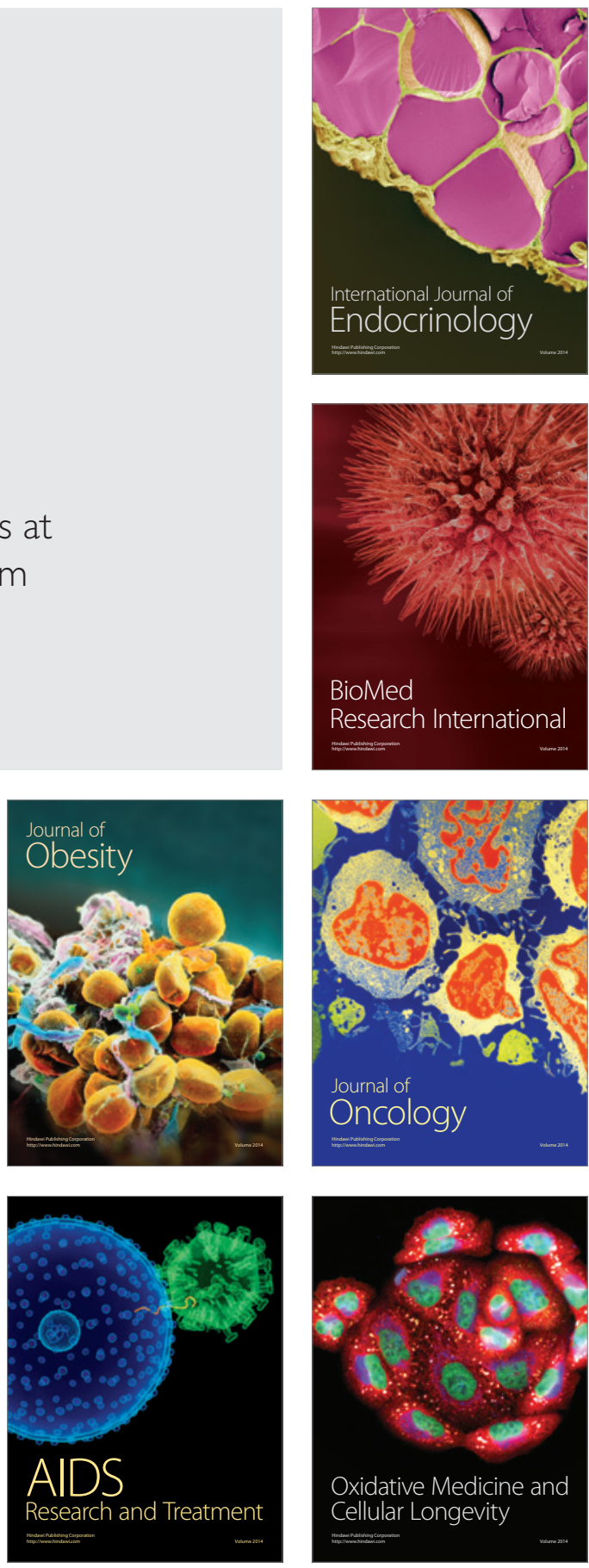